\title{
Nondestructive Evaluation of Pickling Cucumbers Using Visible-Infrared Light Transmission
}

\author{
A. Raymond Miller ${ }^{1}$ and Thomas J. Kelley \\ Department of Horticulture and Crop Science, The Ohio State University, Ohio Agricultural Research and \\ Development Center, Wooster, OH 44691
}

\author{
Brian D. White \\ Research Extension Analytical Laboratory, The Ohio State University, Ohio Agricultural Research and \\ Development Center, Wooster, $\mathrm{OH} 44691$
}

Additional index words. Cucumis sativus, internal quality, mechanical stress, bruising, storage

\begin{abstract}
A nondestructive method was developed utilizing a modified Trebor 101 watercore tester to evaluate the internal quality of pickling cucumbers. The method involved measuring the relative amount of visible-infrared light passing through the longitudinal midsection of whole cucumber fruit. Light transmission was quantified on a unitless sigmoid scale from 1 to 10, with light transmission and scale values positively related. Immediately after hand harvest, size $3 \mathrm{~F}$ (47 to 51 $\mathrm{mm}$ in diameter) cucumbers exhibited transmission values between 2 and 3 , regardless of cultivar. Following a mechanical-stress treatment, which simulated bruising incurred during harvesting and handling of cucumbers, the internal quality of the fruit declined and was associated with an increase to a value of 6 in light transmission compared to non-stressed fruit. Light transmission increased as the severity of stress applied to the fruit increased, and high light transmission values were evident throughout a $48 \mathrm{~h}$ storage period at room temperature. Light transmission values increased as fruit diameter decreased, but values within a particular size class of undamaged, hand-harvested fruit were consistent. Machine-harvested fruit (size 3F), evaluated just before processing, exhibited light transmission values from 2 to 8 , but the majority of fruit fell within the transmission range of 2 to 3 . When fruit exhibiting different light transmission values were speared (cut longitudinally into sixths), processed, and then visually evaluated by panelists, spears prepared from fruit exhibiting high transmission values were judged to be of lower quality than those prepared from fruit exhibiting low transmission values. Visible-infrared light transmission may be a valuable tool for detecting poor quality cucumbers before processing, and could allow the mechanical selection of high quality fruit on a large scale basis.
\end{abstract}

Internal product quality is an important concern of the pickling cucumber industry. The processed product is considered to have high quality if it has seeds intact within the seed cavity, sharp edges at cut surfaces, and firm mesocarp and carpel tissue. By contrast, low quality processed products may have loose seeds or other cucumber tissue floating freely in the jar, ragged edges at cut surfaces, and have damaged or soft regions. These negative qualities can be attributed to environmental factors (Thomas and Staub, 1992), mineral nutrition (Frost and Kretchman, 1989; Staub et al., 1988), harvest methods (Marshall et al., 1972), postharvest handling (Miller et al., 1987), and storage procedures (Miller et al., 1987; Thomas and Staub, 1992) that adversely affect the cucumbers before processing. Since growers and processors cannot control all of these factors to produce a uniformly high quality fruit, cucumbers of high and low quality are present in shipments of fruit destined for processing. Hence, a method to rapidly evaluate the quality of individual cucumbers, with the intent of separating high and low quality fruit before processing, would be of value to the pickling cucumber industry.

Peroxidase activity and delayed light emission (DLE) have been investigated as possible indicators of fresh cucumber quality. Hammerschmidt and Marshall (1991) found that when damaged cucumbers were dipped into a solution of guaiacol and hydrogen peroxide, the solution became darker in color than a solution into

Received for publication 7 Apr. 1995. Accepted for publication 29 June 1995. Salaries and research support provided in part by state and federal funds appropriated to the The Ohio State Univ., Ohio Agricultural Research and Development Center. Journal article no. 178-94. We thank Mark Jameson and Bonnie Borchert for excellent technical assistance. The cost of publishing this paper was defrayed in part by the payment of page charges. Under postal regulations, this paper therefore must be hereby marked advertisement solely to indicate this fact.

'To whom reprint requests should be addressed. which undamaged cucumbers were dipped. This test was based on increased peroxidase activity evident after bruising (Miller and Kelley, 1989), and the water soluble nature of the enzyme. From a practical perspective, the peroxidase method is not desirable since it is slow and the resultant fruit are unsuitable for processing, due to guaiacol contamination. Hence, only a few fruit in a shipment of cucumbers can be evaluated by this method. As an alternative Abbott et al. (1991) tested whether DLE could be used to evaluate fresh cucumber quality. They found that DLE could consistently distinguish bruised from nonbruised cucumbers because nonbruised fruit exhibited significantly higher maximum values for DLE. However, DLE values increased during storage regardless of bruising, and storage temperature significantly affected maximum DLE values. The determination of DLE requires sophisticated instruments and the cucumbers must be stored in the dark for at least one hour before evaluation. Therefore, the DLE method may not be readily applicable to commercial situations.

While conducting research on the effects of bruising on pickling cucumbers Miller et al. (1987) and Abbott et al. (1991) noted that water-soaked lesions were present throughout bruised fruit. Later observations showed that these lesions could be visualized through an infrared lens while the cucumber was backlit or sidelit with an incandescent lamp, and that these bruises were most transparent to light at wavelengths between 900 and $1100 \mathrm{~nm}$ (A.R. Miller and K. Norris, unpublished). These observations led to the hypothesis that infrared light transmission could be used to detect cucumbers with bruises and low internal quality. This paper describes the modification of a Trebor 101 watercore tester, which has output predominately in the infrared region of the light spectrum, for determining relative light transmission through pickling cucumbers. This modified instrument was then used to test the hypothesis that light transmission can be used to evaluate the 
internal quality of cucumbers. We then determined whether spears prepared-from cucumbers exhibiting different light transmission values (LTVs) differed in quality after processing.

\section{Materials and Methods}

Plant material and treatments. Pickling cucumbers used in these studies were hand- or machine-harvested from commercial fields or cultivar performance trial plots in Ohio, Michigan, Illinois and Indiana. Experiments were conducted during the 1986 through 1990 growing seasons. Cucumbers were graded by diameter into the following groups: 1B ( 21 to $27 \mathrm{~mm}), 2 \mathrm{C}$ (28 to $34 \mathrm{~mm}), 2 \mathrm{D}$ ( 35 to $38 \mathrm{~mm}$ ), $3 \mathrm{E}$ ( 39 to $46 \mathrm{~mm}$ ), $3 \mathrm{~F}$ ( 47 to $51 \mathrm{~mm}$ ) and oversize (> 51 $\mathrm{mm})$. Following the measurement of light transmission, some $3 \mathrm{~F}$ cucumbers were cut transversely at the longitudinal median and the diameter of the seed cavity (carpel) and thickness of the fruit wall (mesocarp) were determined.

In some experiments, size $3 \mathrm{~F}$ cucumbers were bruised by rolling them for specified periods of time beneath a wooden board supporting a 10-kg mass (Abbott et al., 1991; Miller et al., 1987). Cucumbers were then stored at $25 \mathrm{C}$ and $100 \%$ relative humidity in the dark for 24 or $48 \mathrm{~h}$.

Light meter modifications and light transmission measurements. A Trebor 101 watercore tester (Trebor Industries, Gaithersburg, Md.) was calibrated according to the manufacturer's instructions and used for preliminary experiments. Once it was determined that the Trebor 101 would detect light transmitted through cucumbers and that variation for amount of light transmitted was present in populations of machine-harvested cucumbers, the Trebor 101 was modified to facilitate its use with cucumbers. Modifications included replacement of the Sylvania no. 5SLB5 light bulb with a Sylvania no. 14FSB5 light bulb, which was fixed inside a chrome reflecting cylinder (19 $\mathrm{mm}$ long $\mathrm{x} 11.8 \mathrm{~mm}$ in diameter) to focus the light beam. The replacement light source also required additional power, therefore a $18-\mathrm{V}$ battery pack was constructed to power the light source. The original $6-\mathrm{V}$ power source was retained to power the light sensitive photodiode, amplifier, voltage comparator integrated circuit (IC), and the LED display. Additionally, the 3914 monolithic IC (dot display driver) was replaced with a 3915 monolithic IC (National Semiconductor Corp., Santa Clara, Calif.). (Note: a schematic diagram of these modifications is available upon request.) After the instrument had been calibrated according to the manufacturer's instructions, differences in detector response between the unmodified and modified Trebor 101 were evaluated using layered ceramic infrared filters (NIR Systems, Silver Spring, Md.)

Light transmission through cucumbers was measured by placing the longitudinal midpoint of a flat surface of the fruit against the light source of the Trebor 101 (thus the opposing angular side was against the photodetector), and then the cucumber and the water core tester were enclosed in heavy black cotton cloth to exclude light while taking measurements. For each cucumber evaluated, this process was repeated at the longitudinal midpoint of the other two flat sides. Hence, the LTV for each cucumber was the mean of three measurements, which was then rounded to the nearest whole number.

Pickle processing and panel evaluation. At a commercial processing plant, size $3 \mathrm{~F}$ cucumbers were speared (cut longitudinally into sixths) and placed into 472-m1(16-oz) jars by a commercial spearing machine. The spears were covered with brine $(43 \mathrm{C}$; containing water, $\mathrm{NaCl}$, vinegar, $\mathrm{CaCl}$, spices, and food coloring), processed at $74 \mathrm{C}$ for $15 \mathrm{~min}$, and cooled to room temperature in a water bath.
Spears in jars were evaluated visually by 12 semi-trained panelists, who frequently participated in sensory evaluation of a variety of horticultural products and who regularly purchased and consumed pickles. Based on their individual criteria to differentiate high and low quality spears, panelists counted the number of low quality spears present around the periphery of each jar. Each panelist then described their primary and secondary criteria to differentiate the spears. Jars had 12. spears around the periphery and each panelist evaluated 12 jars from each LTV group. Jars were coded and presented to panelists in random order. Therefore, the number of low quality spears per jar for each LTV group was the mean of 144 observations. The data were subjected to analysis of variance after square-root transformation due to individual values being small whole numbers (Steel and Torrie, 1980).

\section{Results and Discussion}

Hand-harvested, unbruised cucumbers were slightly transparent to visible and infrared light (Fig. $1 \mathrm{~A}$ and C). Following a bruising treatment, visible and infrared light transmission through
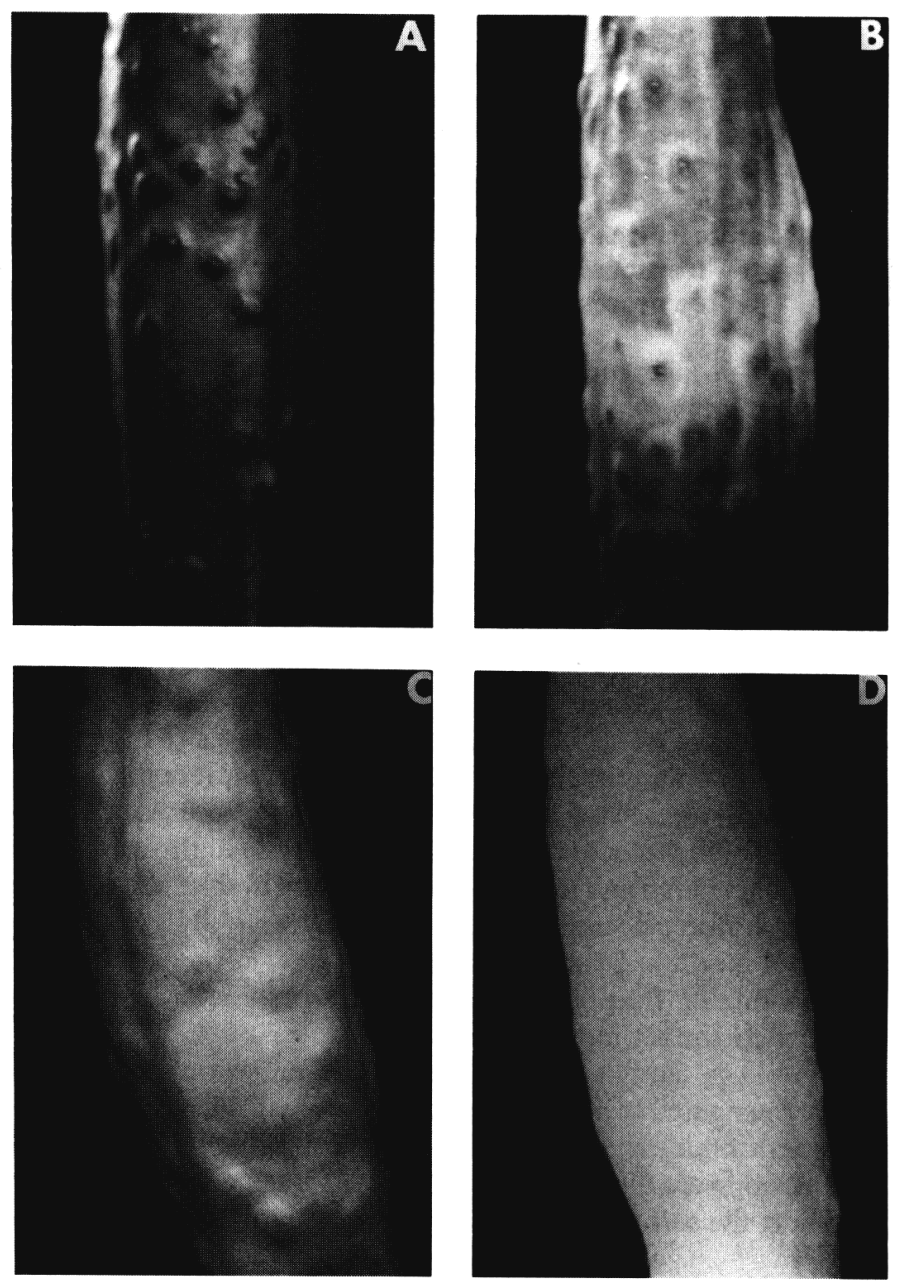

Fig. 1. Photographs of control (A and $\mathbf{C})$ and bruised (B and $\mathbf{D})$ cucumbers backlit with incandescent light then photographed with Kodak 5052 TMX black-andwhite film (A and B; f8,8 s) or Kodak 4143 high-speed IR film (C and D; f2.5, $4 \mathrm{~s})$ to visualize visible and infrared light transmitted through the fruit. Cucumbers were bruised by rolling as described in Materials and Methods. The incandescent light source used for backlighting consisted of a Phillips no. 13186 EPX/EPV bulb and two 5-mm-diameter fiber optic cables. 


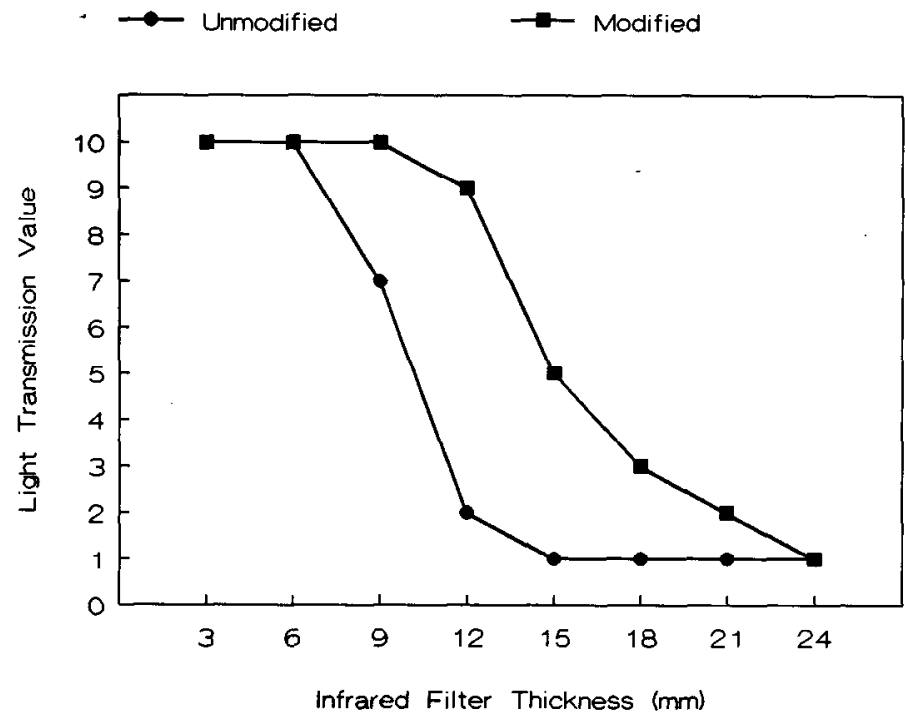

Fig. 2. Light response profile of the manufacturer-supplied (O) and the modified (D) Trebor 101 watercore tester. Modifications to the watercore tester were made as described in Materials and Methods. Neutral-density filtersofvarying thickness were used to obtain a range of transmitted light comparable to that observed in a population of machine-harvested cucumbers. Light transmission is expressed as the unitless value from the LED display of the water core tester. Each point represents the mean of three measurements. For all points, the standard error was smaller than the symbol.

these cucumbers increased dramatically (Fig. 1 B and D). These results suggest that instrumentation capable of detecting light transmitted through cucumbers, particularly infrared wavelengths, could be used to evaluate internal quality changes due to postharvest handling and bruising since it was shown previously that bruising causes tissue separation, carpel degeneration and the formation of water-soaked lesions in pickling cucumbers (Abbott et al., 1991; Miller et al., 1987). Although speculative, tissue separation and water-soaked lesions could account for increased light transmission through bruised cucumbers, by causing cellular components which normally defract or reflect light (e.g., cell walls, starch) to become "wetted" with water from ruptured cells, decreasing their light scattering abilities. In support of this hypothesis, reflective properties of cell walls change when infiltrated with liquids that vary in refractive index (Vogelmann, 1993).

Although designed for use with apples, the Trebor 101 watercore tester is an instrument that could be used to detect visible and nearinfrared light transmission through cucumbers. During preliminary tests we observed that the Trebor 101 (as supplied by the manufacturer) detected light transmitted through mechanicallyharvested cucumbers. Within a sample population of these fruit, light transmission varied among the individual cucumbers (data not shown). Differences were also noted among LTVs done at various locations of individual cucumbers. The ends of fruit exhibited higher light transmission than the middle. Each flat surface of fruit exhibited different LTVs at the longitudinal midpoint. For consistency during all subsequent studies, we measured light transmission at the longitudinal midpoint and across each of the three flat surfaces of the cucumber. This procedure precluded taking measurements at specific bruised or damaged sites on the fruit, thus reducing sampling bias.

A problem encountered during these preliminary tests with the Trebor 101 as supplied was the narrow range of LTVs observed in a sample of over 300 cucumbers which varied widely for internal quality. (Note: light detected by the Trebor 101 is displayed on a unitless scale of 1 to 10 in one unit increments by an LED display;
1 = lowest light transmission, $10=$ highest light transmission.) The majority of fruit $(>95 \%)$ exhibited a LTV of 3, while the remainder exhibited a LTV of 4 . To evaluate populations of fruit with a wide range of internal quality and supposedly a range of light transmission, it was necessary to expand the usable light detection range of the Trebor 101. We accomplished this primarily by replacing the original light bulb and IC. The higher-intensity Sylvania no. 14FSB5 bulb projected more light through fruit than the original bulb. Both bulbs had similar spectral distributions. The original 3914 IC was replaced with a 3915 IC, which has a higher response to low voltage changes than the 3914 IC (National Semiconductor Corp. Data Book 3, 1988).

To compare the light-response profile of the manufacturersupplied and modified Trebor 101, we utilized standard infrared filters. As shown (Fig. 2), light transmission detected by the unmodified, manufacturer-supplied Trebor 101 was maximum when tested with the 3-and 6-mm-thick filters, then decreased rapidly to a minimum at a filter thickness of $15 \mathrm{~mm}$. By contrast, light transmission detected by the modified Trebor 101 was maximum up to a filter thickness of $9 \mathrm{~mm}$, then decreased more slowly to a minimum at a filter thickness of $24 \mathrm{~mm}$. The expanded range of the modified Trebor 101 under high light transmission conditions (filters 3 to $9 \mathrm{~mm}$ thick) was probably due to the use of the higher-intensity light source, while the decreased response slope under low light transmission conditions (filters $15 \mathrm{~mm}$ - to 24 $\mathrm{mm}$ thick) was duetotheuseofthe3915 IC. A semi-logplotoftotal light energy detected vs. filter thickness yielded the linear relationship y $=0.27-0.13 \mathrm{x}$, where $\mathrm{y}$ is $\log \mu \mathrm{mol}$ photons $/ \mathrm{m}^{2}$ per sec and $\mathrm{x}$ is the infrared filter thickness in $\mathrm{mm}$. Hence, a LTV of 3 on the modified Trebor 101, resulting from the use of an 18-mm thick filter, corresponded to $8.5 \mathrm{nmol} \cdot \mathrm{m}^{-2} \cdot \mathrm{s}^{-1}$. This modified Trebor 101 was used during all subsequent experiments.

Our first study compared the LTVs of size $3 \mathrm{~F}$ hand-harvested fruit from eight cucumber cultivars ('Calypso', 'Carolina', 'County Fair', 'Fancipak', 'Heinz 3534', 'Johnston', and 'Poseidon') and six numbered experimental lines. Mean LTVs for the cultivars ranged from $2.2 \pm 0.1(\mathrm{SEM})$ for 'County Fair' to $2.6 \pm 0.1$ for 'Carolina', while those for the numbered lines ranged from $2.5 \pm$ 0.1 to $3.0 \pm 0.0$. In an attempt to explain the variation in LTVs among the 14 cultigens, we plotted fruit wall thickness and carpel diameter against the LTV for individual fruit sampled on two different dates. For fruit wall thickness, $\boldsymbol{r}$ was -0.60 and -0.42 (df =36), respectively, while the $\boldsymbol{r}$ for carpel diameter was 0.21 and 0.14 ( $\mathrm{df}=36)$ for the two dates, respectively. Thus, it appears that for nonbruised cucumbers as fruit wall thickness decreases LTV increases to some extent. On the other hand, carpel diameter has little effect on LTV. It should be noted that fruit wall thickness and carpel diameter were not significantly different among the 14 cultigens, perhaps a result of selection by breeders for pickling cucumbers with consistently thick fruit walls and small seed cells (Staub and Bacher, 1996). Other parameters, such as skin thickness and intensity of skin color were not evaluated, but could affect LTV.

Since light transmission is a negative function of pathlength, we determined the relationship between fruit diameter (grade) and LTV. As expected, LTV increased as fruit diameter decreased. Mean LTVs for hand-harvested 'Flurry' fruit graded into $1 \mathrm{~B}, 2 \mathrm{C}$, $2 \mathrm{D}, 3 \mathrm{E}, 3 \mathrm{~F}$, and oversize groups were 5.6 $\pm 0.2,3.4 \pm 0.2,2.8 \pm 0.2$, $2.7 \pm 0.1,2.5 \pm 0.1$, and $2.2 \pm 0.1$, respectively ( $n=23$ fruit/grade) These data yielded the significant quadratic regression, $\mathrm{y}=7.4 \mathrm{x}^{2}$ $-11.4 \mathrm{x}+6.6(\mathrm{P}=0.05)$. Similar results were obtained for 'Heinz 3534' and 'Carolina'. The LTV of size 1A cucumbers could not be determined due to light leakage around these small diameter fruit. 
The data from this and the genotype experiment show that, within grade classes across cultivars, LTVs are quite consistent. Hence, differences in LTVs among cucumbers within particular grades could suggest differences in the internal quality of the fruit. In our next experiment, we tested this hypothesis by bruising size $3 \mathrm{~F}$ cucumbers, a treatment known to cause internal damage (Abbott et al., 1991; Miller et al., 1987), then determining the LTV of these fruit after specific periods of storage.

Mechanically stressed (bruised) cucumbers exhibited significantly higher LTVs than control fruit (Fig. 3), regardless of time in storage. Further, as the severity of bruising increased, the LTV of the treated fruit increased (data not shown). The LTV of bruised fruit decreased slightly during storage, but was still higher than the LTV of control fruit $48 \mathrm{~h}$ after treatment. This decrease may have been due to wound-healing by the cucumbers, since we have shown previously (Miller et al., 1987) that the water-soaked lesions evident immediately after bruising disappear during storage.

Measurement of LTV of 1927 size 3F cucumbers sampled at a commercial processing plant throughout the 1989 and 1990 harvest seasons showed that significant variation was present in the population sampled (Fig. 4). While the majority of the cucumbers sampled $(58.8 \%)$ exhibited LTVs near 3, LTVs for the population ranged from 2 to 8 . [Note: due to relatively few cucumbers with LTVs $>5$ (1.8\%), these data were pooled in Fig. 4.] This overall population variation can be best explained as the sum of several factors. When one considers that several cultivars of cucumbers were mechanically harvested from many sites at different times, transported by semitrailers to the processing plant, machine graded, and then stored for up to $72 \mathrm{~h}$, the cumulative and interactive effects of a large diameter carpel, a thin mesocarp, bruising, production environment, and genotype become apparent. The low number of cucumbers exhibiting high LTVs was probably due to the removal of these fruit from the sampled population during normal grading and sorting procedures. We evaluated only intact fruit and observed that cucumbers with LTVs $>6$ were usually very soft and watery (Miller and Kelley, unpublished observations). Other severely damaged cucumbers with cuts and cracks were discarded by

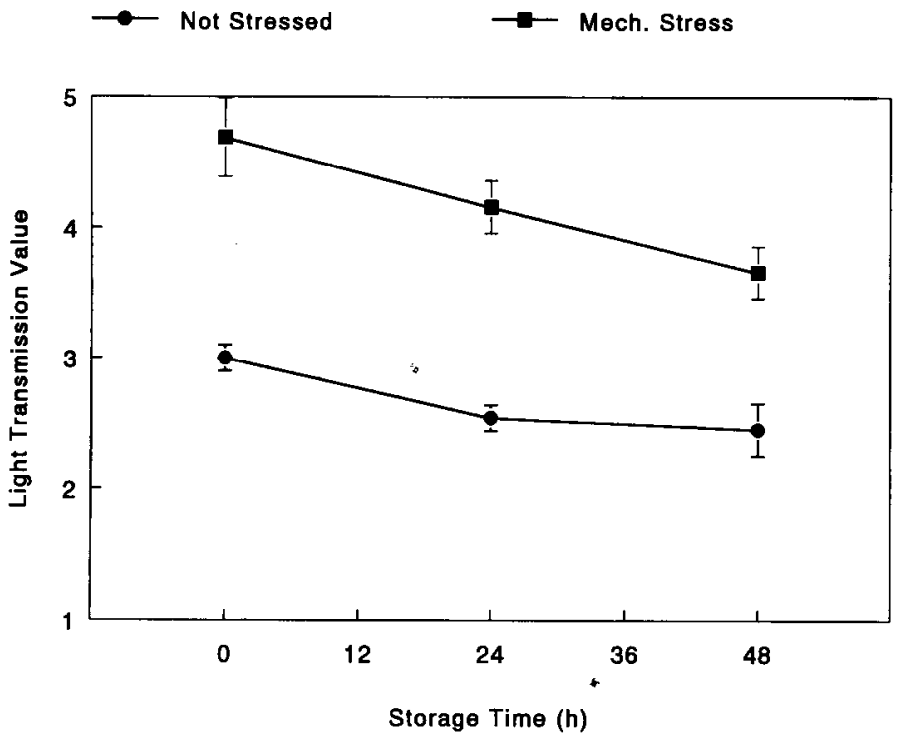

Fig. 3. The effect of bruising (mechanical stress) and length of storage on light transmission through size $3 \mathrm{~F}$ 'Flurry' cucumbers. Cucumbers were bruised, and then stored at $25 \mathrm{C}$ and $100 \%$ relative humidity. At the indicated times, the cucumbers were removed from storage, evaluated using the modified Trebor 101 watercore tester, and then returned to storage. Each point represents the mean of 20 cucumbers; vertical bars represent the standard error.

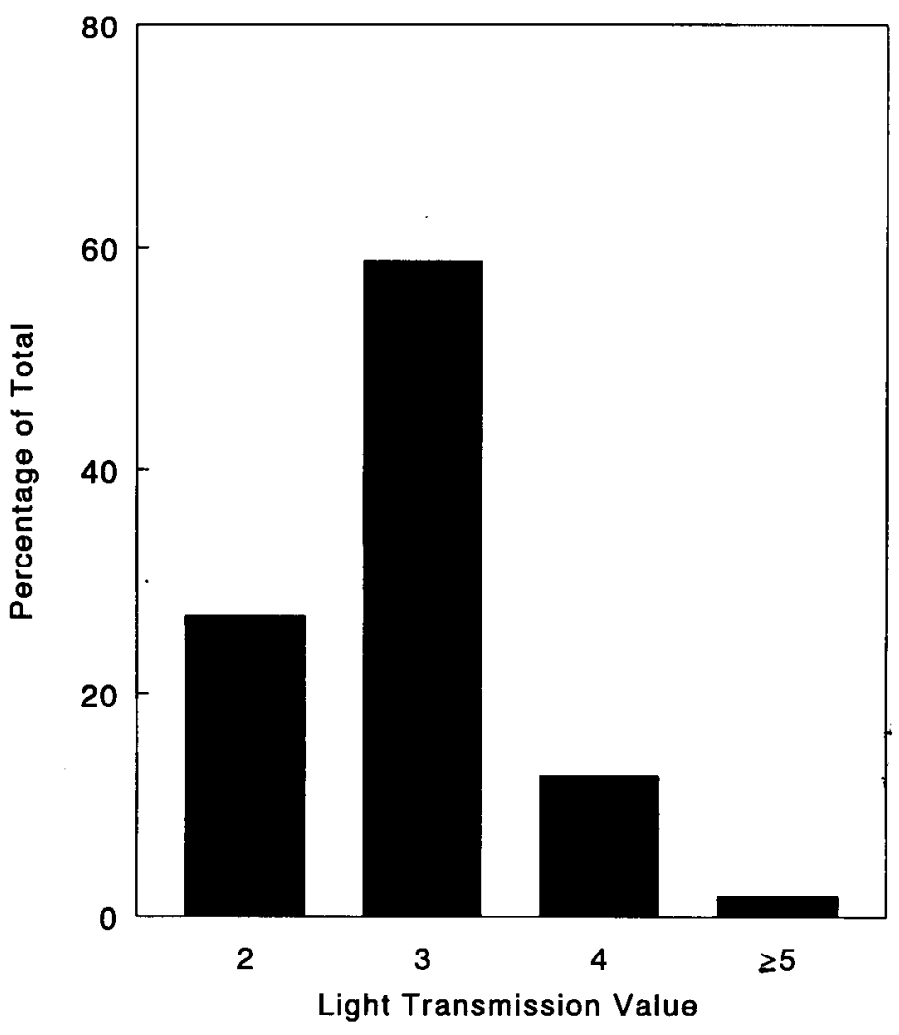

Fig. 4. Cumulative distribution of size $3 \mathrm{~F}$ cucumbers within light transmission value groups throughout the 1989 and 1990 harvest seasons. Cucumbers (mixed cultivars) were machine-harvested from commercial fields in Michigan, Indiana, Illinois, and Iowa; transported to a commercial processing plant; graded by size; placed into $3.3-\mathrm{m}^{3}$ wooden crates; and then evaluated with the modified Trebor 101 watercore tester $(\mathrm{n}=1927)$.

line workers or did not pass through the machine graders and were not evaluated.

After measurement of light transmission, machine-harvested cucumbers from the 1989 and 1990 harvest seasons were segregated into groups based on their LTV, cut into spears, placed into jars, processed, and visually evaluated. Initial observations showed that spears prepared from cucumbers in the various LTV groups differed in quality (Fig. 5). Spears from LTV groups 3 and 24 had ragged cut edges and seeds were floating freely in the jars, while those from LTV group 2 had straight cut edges and few or no freefloating seeds. Further, seeds within the carpel of spears from LTV group 24 appeared to be loose, and the carpel tissue was degenerating. Subsequently, semi-trained panelists evaluated these spears. During the evaluation, all panelists stated that their primary and secondary criteria for differentiating poor from acceptable quality spears was the displacement of seeds from the seed cavity and a damaged seed cell and carpel. Panelist evaluation confirmed that jars containing spears from LTV group 2 had significantly fewer poor quality spears than those in LTV groups 3 and 24 (Table 1). In fact, $92 \%$ of the spears observed in LTV group 24 were judged to be of unacceptable quality, whereas $33 \%$ and $58 \%$ of the spears from LTV groups 2 and 3, respectively, were unacceptable.

Collectively, results from the panelist evaluation and the distribution of cucumbers within the LTV groups suggest that most $3 \mathrm{~F}$ cucumbers will yield unacceptable spears. Seventy-three percent of the cucumbers evaluated had LTVs 23 (Fig. 4). Based on the mean number of poor spears per jar across all LTV groups (Table 1) and the fact that two cucumbers yield the twelve spears at the periphery of the jar, one can calculate that about $61 \%$ of the cucumbers processed yielded poor quality spears. The relatively 


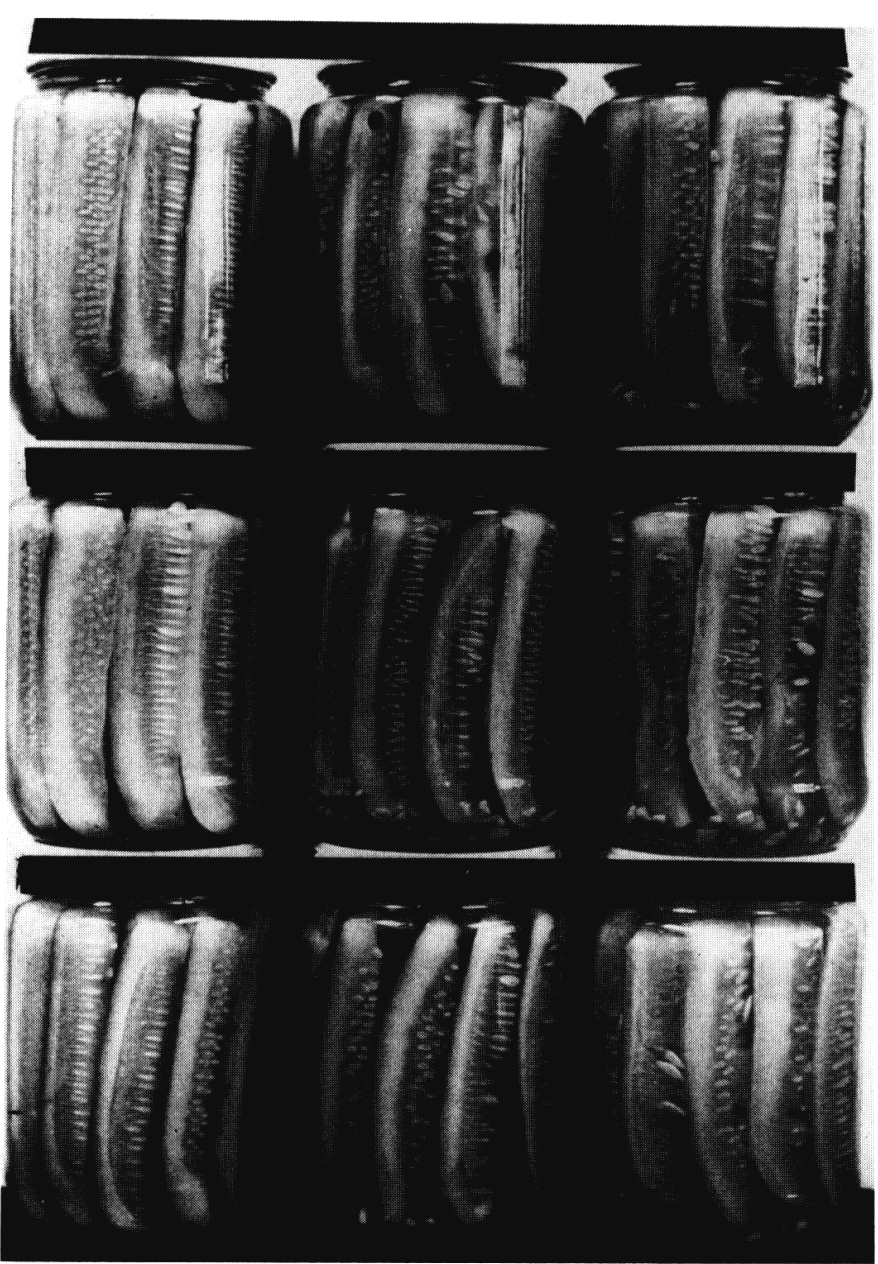

Fig. 5. Representative jars containing fresh-pack pickle spears prepared from grade 3F cucumbers separated into light transmission value groups (see Fig. 4). Columns left to right: light transmission value groups $2,3, \geq 4$.

high occurrence of potentially low quality cucumbers and perceived poor quality spears was probably caused by degeneration of the carpel tissue due to the presence of more mature fruit in this grade $(3 \mathrm{~F})$, as well as harvest and postharvest factors discussed earlier. Cucumbers from other size classes, which represent less ripe fruit, were not processed and evaluated, nor were other types of products (e.g., halves, chips, chunks) that might be prepared from $3 \mathrm{~F}$ cucumbers evaluated. One could postulate that the frequency of low quality cucumbers among younger fruit or in other product types may be lower than that observed for grade $3 \mathrm{~F}$.

To our knowledge, this study represents the first report of visible-infrared light transmission being used to evaluate the internal quality and tissue integrity of a fruit or vegetable destined for processing. Visible light transmission has been used to determine the extent of watercore in fresh market apples (Birth and Olsen, 1964), maturity of tomatoes (Nattuvetty and Chen, 1980) and papaya (Birth et al., 1984), internal color of tomatoes (Worthington et al., 1976), firmness of peaches (Watada et al., 1976), and-the dry matter content of onions (Birth et al., 1985). The use of light transmission to evaluate internal quality has several advantages: 1) it is nondestructive; 2) it is rapid, and; 3) it can be adapted easily to commercial settings if an adequate seal between the light source and the fruit can be achieved. Other methods have inherent limitations. Light reflectance can be used to detect bruised
Table 1. Panelist evaluation of spears prepared from size 3F cucumbers separated into light transmission value groups before processing.

\begin{tabular}{lc}
\hline \hline $\begin{array}{l}\text { Light transmission } \\
\text { value group }\end{array}$ & $\begin{array}{c}\text { No. of poor-quality } \\
\text { spears per jar }\end{array}$ \\
\hline 2 & $4 \pm 1^{y}$ \\
3 & $7 \pm 1$ \\
24 & $11 \pm 0$ \\
\hline
\end{tabular}

${ }^{7}$ Spears were evaluated by semi-trained panelists who counted the number of poor-quality spears observed at the periphery of each jar.

${ }^{\mathrm{y}}$ Each value represents the mean \pm SE of 12 panelists, each of whom evaluated 12 jars from each light transmission value group. Mean separation by Fisher's LSD. LSD $_{0.001}=0.51$.

apples, but the source beam must be focused directly on the bruise for detection (Upchurch et al., 1990). DLE can detect cold-stressed and bruised cucumbers. However, fruit must be stored in the dark for one hour before evaluation, and DLE requires instruments not readily applicable to commercial situations (Abbott et al., 1991). Sonic resonance, by contrast, may have application since it has been used to determine firmness of apples (Abbott et al., 1992) and the internal quality of other fruits and vegetables (Dull, 1986), but has not been commercialized

In summary, it is feasible with the modified Trebor 101 to evaluate the processing quality of pickling cucumbers by measuring the amount of visible-infrared light transmitted through the fresh fruit. Evaluation by light transmission may be less discriminating than visual evaluation, but sensitivity could be improved by further characterizing the quantity and quality of light required. Ultimately, use of this nondestructive method for evaluation coupled with the application of current electronic technology could allow the development of an in-line sorter capable of separating high and low quality cucumbers before processing, which would lead to increased product quality for the consumer and decreased production costs for the processor.

\section{Literature Cited}

Abbott, J.A., H.A. Affeldt, and L.A. Liljedahl. 1992. Firmness measurement of stored 'Delicious' apples by sensory methods, Magness-Taylor, and sonic transmission. J. Amer. Soc. Hort. Sci. 117:590-595.

Abbott, J.A., A.R. Miller, and T.A. Campbell. 1991. Detection of mechanical injury and physiological breakdown of cucumbers using delayed light emission. J. Amer. Soc. Hort. Sci. 116:52-57.

Birth, G.S., G.G. Dull, W.T. Renfroe, andS.J. Kays. 1985. Nondestructive spectrophotometric determination of dry matter in onions. J. Amer. Soc. Hort. Sci. 110:297-302.

Birth, G.S., G.G. Dull, J.B. Magee, H.T. Chan, and C.G. Cavaletto. 1984 An optical method for estimating papaya maturity. J. Amer. Soc. Hort. Sci. 109:62-66.

Birth, G.S. and K.L. Olsen. 1964. Nondestructive detection of water core in Delicious apples. Proc. Amer. Soc. Hort. Sci. 85:74-84.

Dull, G.G. 1986. Nondestructive evaluation of quality of stored fruits and vegetables. Food Technol. 40(5):106-1 10.

Frost, D.J. and D.W. Kretchman. 1989. Calcium deficiency reduces cucumber fruit and seed quality. J. Amer. Soc. Hort. Sci. 114:552-556.

Hammerschmidt, R. and D.E. Marshall. 1991. Potential use of peroxidase in external bruise assessment. Abstracts of the 1991 Pickling Cucumber Improvement Committee Meeting, Louisville, Ky. p. 37.

Marshall, D.E., B.F. Cargill, and J.H. Levin. 1972. Physical and quality factors of pickling cucumbers as affected by mechanical harvesting. Trans. Amer. Soc. Agr. Eng. 15:604-608, 612.

Miller, A.R. and T.J. Kelley. 1989. Mechanical stress stimulates peroxidase activity in cucumber fruit. HortScience 24:650-652.

Miller, A.R., J.P. Dalmasso, and D.W. Kretchman. 1987. Mechanical stress, storage time, and temperature influence cell wall-degrading enzymes, firmness, and ethylene production by cucumbers. J. Amer. 
Soc. Hort. Sci. 112:666-671.

Nattuvetty, V.R. and P. Chen. 1980. Maturity sorting of green tomatoes based on light transmittance through regions of the fruit. Trans. Amer. Soc. Agr. Eng. 23x515-518.

Staub, J.E. and J. Bacher. 1996. Cucumber as a processing vegetable. In: D. Smith (ed.). Processing fruit and vegetables. vol. 4. Technomic Publ. Co., Lancaster, $\mathrm{Pa}$. (In press.)

Staub, J.E., P. Rousos, and B.E. Struckmeyer. 1988. Anatomical characterization and possible role of calcium in "pillowy", a fruit disorder in processing cucumber. J. Amer. Soc. Hort. Sci. 113:905-909.

Steel, R.G.D. and J.H. Torrie. 1980. Principles and procedures of statistics: a biometrical approach, 2nd ed. McGraw-Hill, New York.

Thomas, R.S. and J.E. Staub. 1992. Water stress and storage environment affect pillowy fruit disorder in cucumber. J. Amer. Soc. Hort. Sci. 117:394-399.

Upchurch, B.L., H.A. Affeldt, W.R. Hruschka, K.H. Norris, and J.A. Throop. 1990. Spectrophotometric study of bruises on whole, 'Red Delicious' apples. Trans. Amer. Soc. Agr. Eng. 33:585-589.

Vogelmann, T.C. 1993. Plant tissue optics. Annu. Rev. Plant Physiol. Mol. Biol. 44:231-251.

Watada, A.E., J.A. Abbott, and E.E. Finney. 1976. Firmness of peach measured nondestructively. J. Amer. Soc. Hort. Sci. 101:404-406.

Worthington, J.T., D.R. Massie, and K.H. Norris. 1976. Light transmission technique for predicting ripening time for intact green tomatoes. In: J.J. Caffney (ed.). Quality detection in foods. Amer. Soc. of Agr. Eng., St. Joseph, Mich. 